Check for updates

Cite this: RSC Adv., 2019, 9, 2816

Received 22nd December 2018 Accepted 14th January 2019

DOI: 10.1039/c8ra10506e

rsc.li/rsc-advances

\title{
Environmental separation and enrichment of gold and palladium ions by amino-modified three- dimensional graphene
}

\author{
Jing Li, Shaoxia Wang, Feng Wang, Xuran Wu (D) and Xuming Zhuang (D) *
}

\begin{abstract}
The excellent adsorption properties of three-dimensional graphene (3DG) can be further enhanced by triethylenetetramine modification to increase its adsorption capacity for precious metal ions. Herein, we successfully synthesized an amino-modified 3DG (N-3DG) adsorbent with improved adsorption conditions with regards to $\mathrm{pH}$ value, dosage, and adsorption time. Adsorption equilibrium was reached at pH 3 over 120 min. In addition, the theoretical basis for the adsorption of N-3DG is provided by fitting the adsorption isotherm model. The synthesized material was tested in seawater and lake water samples for the adsorption of precious metals, namely $\mathrm{Au}\left({ }_{11}\right)$ and $\mathrm{Pd}(\Perp)$, achieving a recovery rate of $87 \%$ to $106 \%$ as assessed by inductively coupled plasma mass spectrometry. Thus, N-3DG showed good adsorptivity. The present results indicate that N-3DG materials could have a viable application in environmental and sewage treatment in the near future.
\end{abstract}

\section{Introduction}

Precious metals (Ag, Au, Ru, Rh, Pd, Os, Ir, Pt) have excellent corrosion resistance and highly stable chemical properties and are therefore widely used in various fields including agriculture, biomedicine, jewellery, catalysis, and electronic industries. ${ }^{1}$ To date, various methods are available for their separation and extraction such as ion exchange, ${ }^{2}$ coprecipitation, fire assay, solvent extraction, ${ }^{3,4}$ liquid membrane separation, and adsorbent separation, ${ }^{5}$ among others. In the past, most of the resin used as a matrix, and resin molecules ${ }^{6-8}$ were functionalized with chemical groups able to increase their adsorption capacity for precious metals. The subsequent chelation of precious metal ions from the aqueous solution led to the selective enrichment of metal ions, with their subsequent release under certain conditions. ${ }^{9}$

Recent studies have focused on the separation of adsorbents, as well as on the synthesis of new adsorbents, such as clay minerals, nanosized metal oxides (NMOs), nanoscale zerovalent iron (NZVI), ${ }^{\mathbf{1 0}}$ layered double hydroxides (LDHs), ${ }^{\mathbf{1 1}}$ layered metal sulfides (LMS), metal-organic frameworks (MOFs), ${ }^{\mathbf{1 0 , 1 2}}$ activated carbon (AC), ordered mesoporous carbon (OMC), organic resins, carbon nanotubes (CNTs), graphene oxides (GO), and polymer-based nanocomposites. ${ }^{13}$ These adsorbents are widely used in the removal of heavy metal ions and various pollutants, and achieved better adsorption effect. The adsorption properties of graphene-based materials have been extensively studied in recent years.

College of Chemistry and Chemical Engineering, Yantai University, Yantai, China. E-mail:xmzhuang@iccas.ac.cn
Graphene-based materials have been extensively studied in applications such as electrochemical catalysis, ${ }^{\mathbf{1 4 , 1 5}}$ energy storage, ${ }^{16,17}$ electrochemical sensors, ${ }^{18-22}$ and other aspects. Three-dimensional graphene (3DG) is a recently developed three-dimensional structure carbonaceous material, constructed with small lamellar-size graphene. ${ }^{23}$ Compared to twodimensional graphene, 3DG not only has a highly porous network structure, very low density, good adsorption, and an excellent mass transfer effect, but also has a high elasticity, flexibility, and lightness. ${ }^{24,25}$ Due to its extremely high adsorption capacity, Zheng et al. applied 3DG to the treatment of environmental sewage. ${ }^{26,27}$ Further, Bi et al. ${ }^{28}$ synthesized 3DG with a broad-spectrum absorption to petroleum products, fats, alkanes, toluene, and other organic solvents, without the need for further modification or treatment. The absorption efficiency of 3DG is 20 to 86 times of its weight, similar to or larger than that of polymers and expanded graphite. Zhao et al. ${ }^{29}$ reported the hydrothermal synthesis of 3DG for the removal of $\mathrm{Cu}^{2+}$, achieving a huge adsorption capacity of $228 \mathrm{mg} \mathrm{g}^{-1}, 40$ times higher than that of active carbon. Similarly, Liu et al. ${ }^{30}$ applied 3DG in the removal of methylene blue and methyl violet dyes, which are main contaminants from the dye manufacturing and textile finishing industry. The adsorption process showed that 3DG displays an adsorption capacity as high as 397 and $467 \mathrm{mg}$ $\mathrm{g}^{-1}$ for methylene blue and methyl violet, respectively.

However, in the related literatures, ${ }^{5,31-33}$ few studies are available on the application of carbon nanomaterials in the adsorption of precious metals. In particular, the use of 3DG materials for the simultaneous adsorption of two precious metals has not yet been reported. Due to its porous structure, 3DG has abundant channels to provide storage space for the 
adsorption of precious metals. Therefore, we exploit this adsorptivity in the sequestration of precious metals from environmental samples.

The triethylenetetramine $\left(\mathrm{NH}_{2}\left(\mathrm{CH}_{2}\right)_{2} \mathrm{NH}\left(\mathrm{CH}_{2}\right)_{2} \mathrm{NH}\left(\mathrm{CH}_{2}\right)_{2}-\right.$ $\mathrm{NH}_{2}$, TETA) has many amino groups. Herein, a nucleophilic reaction occurred between the amino and epoxy groups on the surface of graphene oxide (GO). The adsorption site was added to enhance its adsorption ability. ${ }^{34}$ According to Pearson's theory ${ }^{35}$ of hard and soft acids and bases (HSAB), precious metal ions $\mathrm{Au}(\mathrm{III})$ and $\mathrm{Pd}(\mathrm{II})$ belongs to soft acid, and they are easy to coordinate with ligand such as $\mathrm{N}, \mathrm{S}$, and so on, ${ }^{36}$ and form stable chelates. The solitary-pair electrons on the nitrogen atom have certain chelating ability to metal ions, and the precious metals all have the unfilled d orbitals, which is advantageous to the chelation reaction between them. Therefore, the adsorption ability of 3DG to precious metals can be improved by amino modification. The three-dimensional structure was synthesized by a self-assembly hydrothermal reaction and vacuum freezedrying technology for the adsorption of precious metals. ${ }^{37,38}$

\section{Experimental section}

\subsection{Materials and reagents}

GO was purchased from Chengdu Organic Chemicals Co., Ltd. The standard solutions of Au(III) and Pd(II) were supplied by NCS Analytical Instruments Co., Ltd. TETA was bought from Tianjin Pinnacle Chemical Co., Ltd. ( $\geq 95 \%$ purity). Ammonium hydroxide was obtained from International Group Chemical Reagent Co., Ltd. (25-28\% purity). All water in the laboratory was ultrapure water $(18.25 \mathrm{M} \Omega \mathrm{cm})$.

\subsection{Instruments}

The mass of adsorbent was measured using an electronic balance (AR2130, Ohaus International Trade (Shanghai) Co., Ltd.) with an accuracy of $0.1 \mathrm{mg}$. $\mathrm{pH}$ measurements were performed using a digital $\mathrm{pH}$ meter (PHS-3C, Shanghai, China). The metal ion concentrations were determined by inductively coupled plasma atomic emission spectrometry (ICP-AES; ICAP6300, Thermo Electron Corporation, USA) and inductively coupled plasma mass spectrometry (ICP-MS, Agilent 7700x, Agilent, USA).

Fourier-transform infrared spectroscopy (FT-IR) was performed on a FTIR-84005 (Shimadzu, Japan) spectrometer. Scanning electron microscopy (SEM) images were obtained using a field emission scanning electron microanalyzer (S-4800, Hitachi, Japan). X-ray diffraction (XRD) measurements were obtained using an X-ray diffractometer to determine the crystal phase composition of the sample (XRD6000, Shimadzu, Japan). X-ray photoelectron spectra (XPS) analysis was tested with an ESCALAB 250Xi (Thermo, USA). Elemental content analysis by CHN elemental analysis with EURO EA 3000 (Iveco, Italy). Brunauer-Emmett-Teller (BET) used to measurement of the specific surface area of materials (ASAP2020, Micromeritics, USA). Hydrothermal reactors (KLJX-8A, Yantai, China) and vacuum freeze dryers (GLZ-0.4 Shanghai) were used for the synthesis of the materials, and a water-bathing constant temperature vibrator (DKZ-2, Shanghai, China) was used in the adsorption experiments.

\subsection{Synthesis of amino-modified 3DG (N-3DG)}

GO (200 mg) was dissolved in $25.0 \mathrm{~mL}$ of ultrapure water for $30 \mathrm{~min}$ and transferred into the inner tank of a polytetrafluoroethylene reactor, followed by the addition of $6.0 \mathrm{~mL}$ of TETA. Ammonium hydroxide $\left(0.1 \mathrm{~mol} \mathrm{~L}^{-1}\right)$ was used to adjust the $\mathrm{pH}$ at 11 . The inner tank was placed within the stainlesssteel hydrothermal reactor and heated at $180{ }^{\circ} \mathrm{C}$ for $24 \mathrm{~h}$. The tank was then removed and cooled to room temperature, then wash it with ultrapure water for three times.

$\mathrm{N}-3 \mathrm{DG}$ was then freeze-dried for $72 \mathrm{~h}$, producing a dry and loose porous N-3DG powder.

\subsection{Adsorption studies}

Adsorption experiments were performed using the batch method, wherein a given amount of $\mathrm{N}-3 \mathrm{DG}$ was added to $15.0 \mathrm{~mL}$ of $5.0 \mu \mathrm{g} \mathrm{mL}{ }^{-1} \mathrm{Au}(\mathrm{III})$ and $\mathrm{Pd}(\mathrm{II})$ standard solutions mixture, changed the $\mathrm{pH}\left(1 \mathrm{~mol} \mathrm{~L}^{-1}\right.$ hydrochloride and ammonium hydroxide) and the amount of adsorbent. The mixtures were placed in constant oscillation at $120 \mathrm{rpm}$ in a vibrator. The concentration of $\mathrm{Au}(\mathrm{III})$ and $\operatorname{Pd}(\mathrm{II})$ ions in the solution were determined by ICP-AES. Under the same conditions, standard solutions of $\mathrm{Au}(\mathrm{III})$ and $\mathrm{Pd}(\mathrm{II})$ without any adsorbent were used as blank controls. The effects of $\mathrm{pH}$ value, dosage, and adsorption time as fellow on the adsorption rate were investigated. The standard solutions used for adsorption were all from standard solution $\left(1000 \mathrm{mg} \mathrm{L}^{-1}\right)$ dilution. The adsorption capacity was calculated according to the following formulae: ${ }^{39}$

$$
\begin{gathered}
\qquad q_{\mathrm{e}}=\frac{\left(C_{0}-C_{\mathrm{e}}\right) v}{m} \\
\text { adsorption rate }(\%)=\frac{\left(C_{0}-C_{\mathrm{e}}\right)}{C_{0}} \times 100 \% \\
\text { desorption rate }(\%)=\frac{C_{\mathrm{e}}^{\prime} v}{q_{\mathrm{e}} m} \times 100 \%
\end{gathered}
$$

where $q_{\mathrm{e}}\left(\mathrm{mg} \mathrm{g}^{-1}\right)$ is the adsorption capacity of the adsorbent, $C_{0}$ $\left(\mathrm{mg} \mathrm{L}^{-1}\right)$ and $C_{\mathrm{e}}\left(\mathrm{mg} \mathrm{L}^{-1}\right)$ are the initial and final concentrations of metal ions in aqueous solution, respectively, $C_{\mathrm{e}}^{\prime}\left(\mathrm{mg} \mathrm{L}^{-1}\right)$ is the concentration of precious metals in the solution after elution, $v(\mathrm{~L})$ is the volume of the aqueous solutions, and $m(\mathrm{~g})$ is the mass of the adsorbent.

\section{Results and discussion}

\subsection{Characterization of N-3DG}

Characterization of synthesized N-3DG by SEM, XPS, BET, FT-IR and XRD, CHN. SEM image of GO (Fig. 1A) and N-3DG (Fig. 1B) showed the wrinkled structure of the GO and network structure of N-3DG, respectively. This observation was attributed to the surface defects caused by the oxidation of graphene, resulting in wrinkle curl, bringing in oxygen-containing functional groups ${ }^{\mathbf{4 0}}$ providing more reaction sites. ${ }^{41}$ The structures contribute to the 


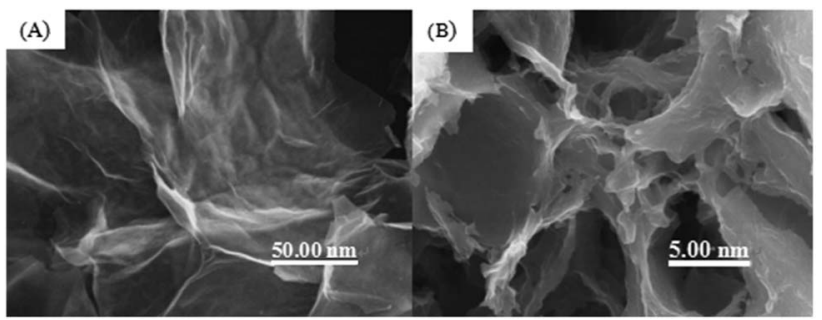

Fig. 1 SEM images of (a) GO, (b) N-3DG.

large surface area of N-3DG, and exhibited cross-linking between the sheets to form a three-dimensional network structure, leading to the formation of pores and increasing the specific surface area of the material. The specific surface area of the N-3DG was measured by $\mathrm{N}_{2}$ adsorption-desorption experiment. The specific surface area of the N-3DG was $291.592 \mathrm{~m}^{2}$ $\mathrm{g}^{-1}$ under the condition of adsorption isotherm at $77 \mathrm{~K}$. The pore volume and pore size are $0.843 \mathrm{~cm}^{3} \mathrm{~g}^{-1}, 5.623 \mathrm{~nm}$ and consistent with SEM results. The results showed that the N-3DG has large specific surface area. The larger the specific surface area, the more the adsorption sites are, and the adsorption capacity of theoretically adsorbent material is greater.

FT-IR spectra of GO showed the characteristic absorption peaks of GO, namely the stretching vibration absorption peak of the $\mathrm{O}-\mathrm{H}$ group at $3432 \mathrm{~cm}^{-142}$ and the $\mathrm{C}=\mathrm{O}$ stretching vibration absorption peak at $1727 \mathrm{~cm}^{-143,44}$ (Fig. 2A(a)), indicating that the GO contains more oxygen-containing functional groups. FTIR spectra of N-3DG showed the characteristic absorption peaks of the $\mathrm{C}-\mathrm{H}$ stretching vibration of $\mathrm{CH}_{2}$ at $2975 \mathrm{~cm}^{-1}$ and $2915 \mathrm{~cm}^{-1}$, the $\mathrm{C}-\mathrm{N}$ stretching vibration absorption peak at $1038 \mathrm{~cm}^{-1}$, as well as the $\mathrm{N}-\mathrm{H}$ vibration and $\mathrm{C}-\mathrm{N}$ stretching vibration absorption peaks of $\mathrm{C}-\mathrm{NH}-\mathrm{C}$ at $1650 \mathrm{~cm}^{-1}$ and
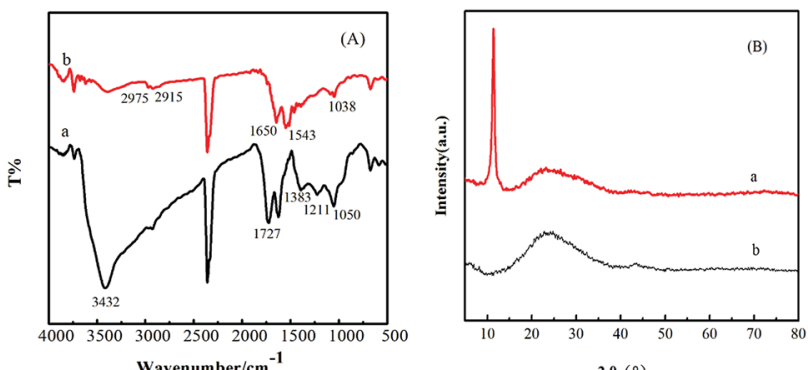

$2 \theta(0)$
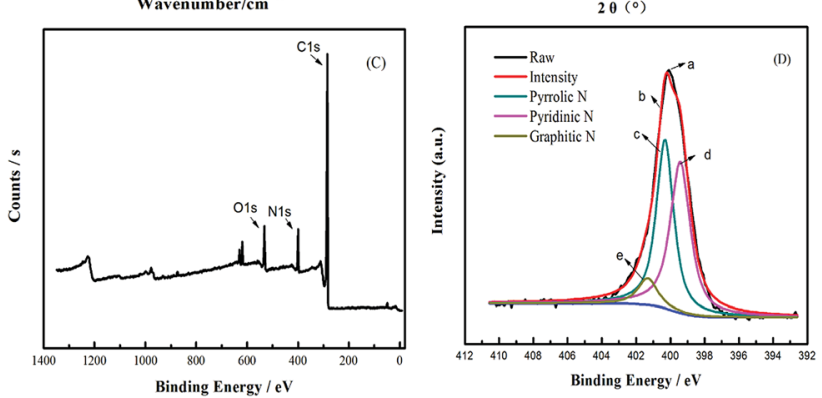

Fig. 2 (A) FT-IR and (B) XRD spectra of (a) GO, (b) N-3DG, respectively. The (C) XPS spectra and (D) N1s region of N-3DG.
$1543 \mathrm{~cm}^{-1}$, respectively (Fig. 2A(b)). Conversely, the sharp characteristic absorption peak intensity of the epoxy group at $1038 \mathrm{~cm}^{-1}$ was weakened, indicating that TETA was functionalized onto the GO surface through chemical bond formation.

The XRD pattern of GO showed a very sharp peak at $2 \theta=$ $11.3^{\circ}$, which is characteristic for the (001) plane of graphene, with broad and strong diffraction occurring at $2 \theta=24.9^{\circ}$ attributed to the graphene (002) plane (Fig. 2B(a)). The (001) peak of GO disappeared in N-3DG, while a higher peak appeared at $25.2^{\circ}$ (Fig. $2 \mathrm{~B}(\mathrm{~b})$ ), indicating that hydrothermal synthesis led to the reduction of GO. ${ }^{45}$ Thus, the results showed that the GO sheet was peeled off and therefore the GO surface was modified.

In order to further prove the synthetic material, the N-3DG was tested by XPS. Fig. $2 \mathrm{C}$ is the full spectrum of N-3DG. It can be observed from Fig. $2 \mathrm{C}$ that there is peak at the binding energy of $285 \mathrm{eV}, 400 \mathrm{eV}, 532 \mathrm{eV}$, corresponding to C1s, N1s and O1s orbitals, respectively. The N1s peak in $399.1 \mathrm{eV}$ shows that $\mathrm{N}$ atom is doped into the graphite thin crystal structure. The high-resolution XPS spectrum of N1s (Fig. 2D) as shown, in which the peaks of N1s can be broken down into three peaks at $398.2 \mathrm{eV}, 399.5 \mathrm{eV}$, and $401.3 \mathrm{eV}$. The nitrogen element has three different forms. Where $398.2 \mathrm{eV}$ corresponds to pyridinic N, $399.5 \mathrm{eV}$ to pyrrolic $\mathrm{N}, 401.3 \mathrm{eV}$ to graphitic $\mathrm{N}^{46,47} \mathrm{At}$ the same time, the content of $\mathrm{C}$ atom was calculated to be $71.78 \%$ and the content of $\mathrm{N}$ atom was $3.08 \%$ and the content of $\mathrm{N}$ atom was $12.46 \%$ by $\mathrm{CHN}$ element analysis.

Combined with the above characterization methods, we successfully modified graphene oxide and synthesized threedimensional structure.

\subsection{Effect of $\mathrm{pH}$, adsorption time, and dosage on adsorption}

The experimental results showed that the optimum $\mathrm{pH}$ for adsorption of $\mathrm{Au}(\mathrm{III})$ and $\mathrm{Pd}(\mathrm{II})$ by N-3DG was within the ranges of 2.0 to 4.0 and 3.0 to 5.0 , respectively. The adsorption rate of
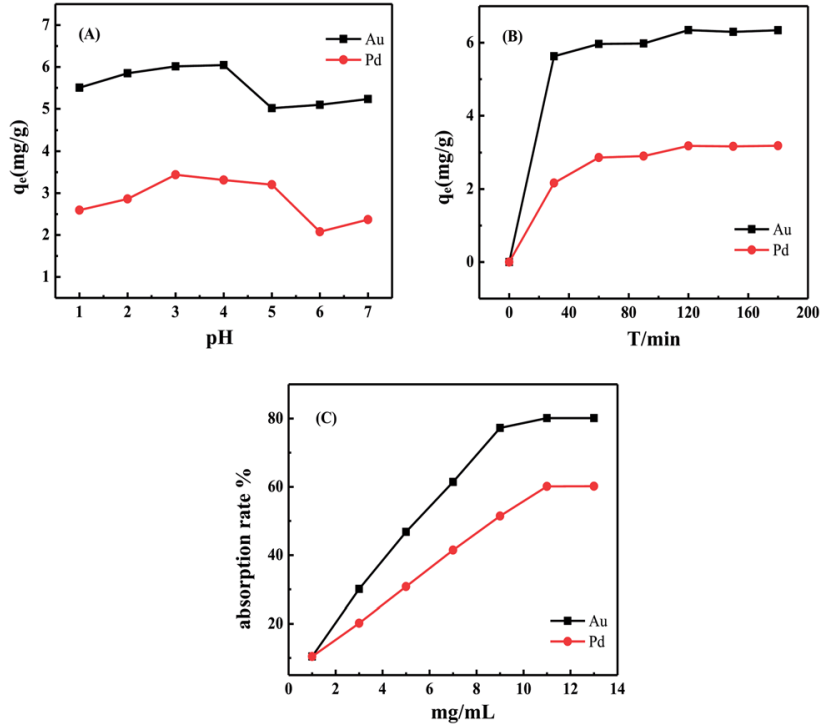

Fig. 3 Effect of $\mathrm{pH}(\mathrm{A})$, adsorption time (B) and dosage (C) on adsorption by N-3DG at $298 \mathrm{~K}$. 
$\mathrm{Au}$ (III) was slightly higher than that of Pd(II) (Fig. 3A). Changes in $\mathrm{pH}$ had a great effect on the adsorption of composite materials. The selective adsorption depends on the properties of the complex groups, the electronic configuration of metal elements, and the composition of the measured components of the complexes. ${ }^{49}$ Meanwhile, the adsorption of precious metal ions by adsorbents depends largely on the valence state of the metal ions. ${ }^{48}$ Formation of chloride complex anion valence state by precious metal ions and hydrochloric acid (low $\mathrm{pH}$ ), coordination might occur between amino group and valence state of chloro complex anion. ${ }^{50}$ In order to obtain the proper valence state of the metal ions, and for the purpose of adsorption the two precious metals simultaneously. Therefore, a $\mathrm{pH}$ value of 3 was chosen as the ideal adsorption acidity.

The adsorption capacity of N-3DG for precious metal ions was dependent on adsorption time (Fig. 3B). As the adsorption reaction time increased, the adsorption rate also increased relatively rapidly up to $60 \mathrm{~min}$, reaching an adsorption equilibrium at $120 \mathrm{~min}$. Therefore, the optimal adsorption time was determined to be $120 \mathrm{~min}$.

With regards to the optimization of adsorbent dosage, the adsorption rate of the two precious metals increased with increasing $\mathrm{N}-3 \mathrm{DG}$ concentration at $\mathrm{pH}=3$ and an initial concentration of $5 \mu \mathrm{g} \mathrm{mL} \mathrm{m}^{-1}$ (Fig. 3C). When the dosage reached $5.0 \mathrm{mg} \mathrm{mL} \mathrm{m}^{-1}$, the adsorption amount reached a maximum value, with no further increases regardless of increasing adsorbent concentration.

\subsection{Isotherms}

The adsorption isotherm is used to describe the adsorption equilibrium and the interaction between adsorbents and adsorbents. The Langmuir adsorption model assumes that monolayers are adsorbed, and the adsorbed molecules do not interact with the molecules in the solution to form an immobile adsorption layer. The Freundlich adsorption model assumes that adsorption occurs on the heterogeneous surface and the adsorption process occurs in the multimolecular layer.

The adsorption of metal ions on N-3DG was simulated using the Langmuir and Freundlich equations, as follows: ${ }^{51}$

$$
\begin{gathered}
q_{\mathrm{e}}=q_{\mathrm{m}} K_{\mathrm{L}} C_{\mathrm{e}} /\left(1+K_{\mathrm{L}} C_{\mathrm{e}}\right) \\
\ln q_{\mathrm{e}}=\ln K_{\mathrm{F}}+\frac{1}{n} \ln C_{\mathrm{e}}
\end{gathered}
$$

where $q_{\mathrm{m}}\left(\mathrm{mg} \mathrm{g}^{-1}\right)$ is the maximum amount of metal ions adsorbed per unit weight of N-3DG at the equilibrium ion concentration, $K_{\mathrm{L}}$ is a constant related to the free energy of adsorption, and $K_{\mathrm{F}}$ and $n$ are Freundlich constants related to the adsorption capacity and the adsorption intensity, respectively.

Isotherm parameters were obtained by fitting the adsorption equilibrium data to the isotherm models (Fig. 4 and isotherm parameters in Table 1). According to the linear correlation coefficient $\left(R^{2}\right)$, the degree of conformity of the model to the experimental data is judged. It is calculated that the corresponding $R^{2}$ is larger, indicating that the adsorption process is more consistent. According to Table 1, the Langmuir adsorption isotherm model of $\mathrm{Au}(\mathrm{III}), \mathrm{Pd}(\mathrm{II})$ (Fig. $4 \mathrm{~A}$ and $\mathrm{C}$ ) obtained $R^{2}$ of
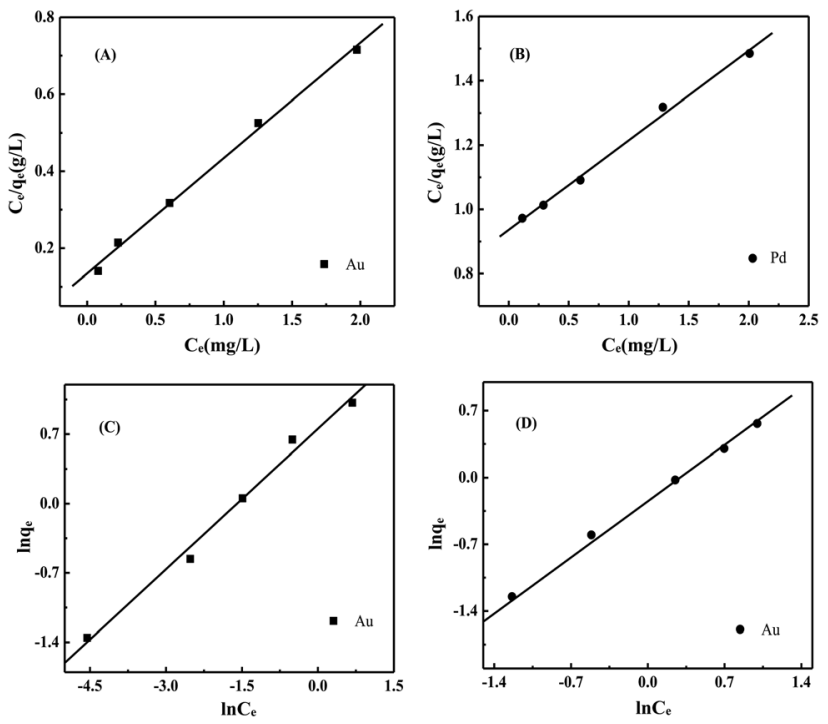

Fig. 4 Adsorption isotherms model for $\mathrm{Au}(\mathrm{II})$ and $\mathrm{Pd}(॥)$ onto N-3DG $\left(0.2 \mathrm{mg} \mathrm{L}^{-1}\right.$ to $4.0 \mathrm{mg} \mathrm{L}^{-1}$ ) at $\mathrm{pH}=3,2 \mathrm{~h}, 298 \mathrm{~K}$. (A) and (B) are the Langmuir isotherm models of $\mathrm{Au}(\mathrm{III})$ and $\mathrm{Pd}(\mathrm{II})$. (C) and (D) are the Freundlich isotherm models of $\mathrm{Au}(\mathrm{III})$ and $\mathrm{Pd}(\mathrm{II})$, respectively.

0.9773 and 0.9669 , respectively, and Freundlich isothermal model (Fig. 4B and D) fitted $R^{2}$ were 0.9914 and 0.9972 , respectively. The data indicated a better fit by the Freundlich adsorption isotherm model for the adsorption of $\mathrm{Au}(\mathrm{III}), \mathrm{Pd}(\mathrm{II})$ by $\mathrm{N}$-3DG, likely due to monolayer adsorption. The values of $n$ are all greater than 1 , indicating that both $\mathrm{Au}(\mathrm{III})$ and $\mathrm{Pd}(\mathrm{II})$ are easily adsorbed.

Further, $K_{\mathrm{F}}$ is a relative adsorption capacity, and the larger the $K_{\mathrm{F}}$, the easier the adsorption is at the equilibrium concentration. It can be seen from Table 1 that the $K_{\mathrm{F}}$ of $\mathrm{Au}(\mathrm{III})$ is 2.1261, and the $K_{\mathrm{F}}$ of $\mathrm{Pd}(\mathrm{II})$ is 0.7804 . In combination with Fig. 3C, the adsorption rate of $\mathrm{Au}(\mathrm{III})$ is greater than the adsorption rate of $\mathrm{Pd}(\mathrm{II})$, which indicate the adsorption of the adsorbent on $\mathrm{Au}(\mathrm{III})$ is easier.

The results indicate that both $\mathrm{Au}(\mathrm{III})$ and $\mathrm{Pd}(\mathrm{II})$ are easily adsorbed, suggesting a chemical adsorption process, wherein the metal ions are chelated onto the N-3DG surface.

\subsection{Influence of interference ions on adsorption properties}

The effects of interference ions on the adsorption properties of $\mathrm{Au}(\mathrm{III})$ and $\mathrm{Pd}$ (II) were investigated by simulated experiments. The concentrations of $\mathrm{Au}(\mathrm{III})$ and $\mathrm{Pd}(\mathrm{II})$ in solution were both $0.5 \mathrm{mg} \mathrm{L} \mathrm{L}^{-1}$. Adding $\mathrm{N}-3 \mathrm{DG}$ adsorbents was $11 \mathrm{mg}$, the

Table 1 Adsorption isotherm parameters for $\mathrm{Au}$ (III), Pd(II) onto N-3DG (0.2 $\mathrm{mg} \mathrm{L}^{-1}$ to $4.0 \mathrm{mg} \mathrm{L}^{-1}$ ) at $\mathrm{pH}=3,2 \mathrm{~h}, 298 \mathrm{~K}$

\begin{tabular}{lllllllll}
\hline & \multicolumn{3}{l}{ Langmuir } & & & \multicolumn{2}{l}{ Freundlich } \\
\cline { 2 - 3 } Ions & $q_{\mathrm{m}}$ & $K_{\mathrm{L}}$ & $R^{2}$ & & $K_{\mathrm{F}}$ & $n$ & $R^{2}$ \\
\hline $\mathrm{Au}(\mathrm{III})$ & 3.1104 & 3.1123 & 0.9773 & 2.1261 & 2.1177 & 0.9914 \\
$\operatorname{Pd}(\mathrm{II})$ & 4.2535 & 0.2443 & 0.9689 & 0.7804 & 1.1868 & 0.9972
\end{tabular}


Table 2 Actual sample measured value and recoveries $(\%)(n=6)$

\begin{tabular}{lllll}
\hline Samples & Ions & $\begin{array}{l}\text { Add amount } \\
\left(\mu \mathrm{gL}^{-1}\right)\end{array}$ & $\begin{array}{l}\text { Actual value } \\
\left.(\mu \mathrm{g} \mathrm{mL})^{-1}\right)\end{array}$ & $\begin{array}{l}\text { Recovery } \\
(\%)\end{array}$ \\
\hline Lake & $\mathrm{Au}(\mathrm{III})$ & 0 & - & - \\
& & 2 & 1.91 & 96 \\
& & 5 & 4.60 & 92 \\
& & & - & - \\
Seawater & & 2 & 2.12 & 106 \\
& & 5 & 4.52 & 90 \\
& & 0 & - & - \\
& & 2 & 1.94 & 97 \\
& & 5 & 4.76 & 95 \\
& & 0 & - & - \\
& & 2 & 1.73 & 87 \\
& & 5 & 4.67 & 93
\end{tabular}

experimental results showed that the interference ion included $\mathrm{Zn}$ (II), $\mathrm{Mg}$ (II), $\mathrm{Fe}$ (III) and $\mathrm{Ca}$ (II), $\mathrm{Cu}(\mathrm{II}), \mathrm{Al}(\mathrm{III}), \mathrm{K}^{+}, \mathrm{Na}^{+}$, were 20 times and 100 times respectively. There was no interference in the determination of $\mathrm{Au}(\mathrm{III})$ and $\mathrm{Pd}(\mathrm{II})$.

\subsection{Eluent experiment}

The adsorption of Au(III) was facilitated by its complexation with the $-\mathrm{NH}_{2}$ functional group of TETA to form a stable complex. Therefore, hydrochloric acid $(15.0 \mathrm{~mL})$ and thiourea $\left(1 \mathrm{~mol} \mathrm{~L}^{-1}\right.$, $1: 1)$ were used as the adsorbents to investigate the desorption effect of precious metals $\mathrm{Au}(\mathrm{III})$ and Pd(II) adsorbed by N-3DG.

\subsection{Application to real samples}

Environmental water samples were retrieved from Sanyuan Lake of Yantai University (lake water) and the East Gate Beach of Yantai University (sea water) to assess the systems applicability in real conditions.

The experiments were performed using $500 \mathrm{~mL}$ of the water samples and static placement for $2 \mathrm{~h}$. A $15.0 \mathrm{~mL}$ sample of the supernatant was placed in the Teflon tank for microwave digestion and cooled to room temperature for use. The alternating magnetic field produced by microwave makes the medium molecules ionize. The sample preparation time is shortened to ensure the accuracy of the test results. Subsequently, $5.0 \mathrm{mg} \mathrm{mL}{ }^{-1}$ of N-3DG were ultrasonically dispersed for $30 \mathrm{~min}$, added $15.0 \mathrm{~mL}$ treated lake samples, and the $\mathrm{Au}(\mathrm{III})$ and $\mathrm{Pd}(\mathrm{II})$ standard solution mixture $\left(2.0 \mu \mathrm{g} \mathrm{mL} \mathrm{mL}^{-1}\right.$ and $5.0 \mu \mathrm{g}$ $\mathrm{mL}^{-1}$, respectively) was added. The $\mathrm{pH}$ was adjusted to 3.0 and the solution was shaken for $120 \mathrm{~min}$. The aqueous solution was then vacuum-filtered and the residue was eluted with hydrochloric acid and thiourea $\left(1 \mathrm{~mol} \mathrm{~L}^{-1}, 1: 1\right)$ for $120 \mathrm{~min}$. The $\mathrm{Au}(\mathrm{III})$ and $\mathrm{Pd}(\mathrm{II})$ contents in the filtrate were measured by ICPMS and the elution rate was calculated. The results (Table 2) showed that the recovery rates were all above $80 \%$.

\section{Conclusions}

Herein, we synthesized an material, N-3DG, with a suitable adsorption capacity for precious metals. $-\mathrm{NH}_{2}$ modification on the surface of graphene and the formation of a rich three- dimensional pore structure were confirmed by SEM, XPS, BET, FT-IR and XRD, CHN. Combined with the above characterization methods, N-3DG was synthesized successfully. The most suitable conditions for the adsorption of $\mathrm{Au}(\mathrm{III})$ and $\mathrm{Pd}(\mathrm{II})$ by $\mathrm{N}$ 3DG were at a $\mathrm{pH}$ of 3.0, reaching adsorption equilibrium after 120 min. The adsorption of $\mathrm{Au}(\mathrm{III}), \mathrm{Pd}(\mathrm{II})$ was better fitted by a Freundlich isotherm, which might be multi-molecular adsorption. And it could be eluted by an eluent of thiourea and hydrochloric acid. In addition, it was applied to the adsorption separation of actual samples, the results showed that the recovery rates were all above $80 \%$, thus demonstrating that N-3DG could be applied to the adsorption of actual samples.

\section{Conflicts of interest}

The authors declare no conflict of interest.

\section{Acknowledgements}

This work was financially supported by the National Natural Science Foundation of China (21575122, 21778047).

\section{References}

1 D. Nagai and T. Kimoto, RSC Adv., 2016, 6, 103304.

2 A. Nalaparaju and J. Jiang, J. Phys. Chem. C, 2012, 116, 6925.

3 H. Hasegawa, S. Barua, T. Wakabayashi, A. Mashio, T. Maki, Y. Furusho and I. M. M. Rahman, Microchem. J., 2018, 139, 174.

4 M. Tian, F. Mu, Q. Jia, X. Quan and W. Liao, J. Chem. Eng. Data, 2011, 56, 2225.

5 L. Liu, C. Li, C. Bao, Q. Jia, P. Xiao, X. Liu and Q. Zhang, Talanta, 2012, 93, 350.

6 Y. Bulut and Z. Baysal, J. Environ. Manage., 2006, 78, 107.

7 F. Xie, Z. Fan, Q. Zhang and Z. Luo, J. Appl. Polym. Sci., 2013, 130, 3937.

$8 \mathrm{H}$. Zhang and D. B. Dreisinger, Hydrometallurgy, 2004, 72, 225.

9 H. Wang, C. Bao, F. Li, X. Kong and J. Xu, Microchim. Acta, 2010, 168, 99.

10 Y. Wu, H. Pang, Y. Liu, X. Wang, S. Yu, D. Fu, J. Chen and X. Wang, Environ. Pollut., 2019, 246, 608.

11 P. Gu, S. Zhang, X. Li, X. Wang, T. Wen, R. Jehan, A. Alsaedi, T. Hayat and X. Wang, Environ. Pollut., 2018, 240, 493.

12 J. Li, X. Wang, G. Zhao, C. Chen, Z. Chai, A. Alsaedi, T. Hayat and X. Wang, Chem. Soc. Rev., 2018, 47, 2322.

13 G. Zhao, X. Huang, Z. Tanga, Q. Huang, F. Niua and X. Wang, Polym. Chem., 2018, 9, 3562.

14 D. Jang, S. Lee, S. Kim, K. Choi, S. Park, J. Oh and S. Park, ChemNanoMat, 2018, 4, 118.

15 X. Zhang, D. Liu, L. Yang, L. Zhou and T. You, J. Mater. Chem. A, 2015, 3, 10031.

16 H. Wang, X. Yuan, Z. Zeng, Y. Wu, Y. Liu, Q. Jiang and S. Gu, Adv. Colloid Interface Sci., 2016, 47, 41.

17 I. V. Lightcap and P. V. Kamat, Acc. Chem. Res., 2013, 46, 2235. 
18 F. Luan, S. Zhang, D. Chen, K. Zheng and X. Zhuang, Talanta, 2018, 182, 529.

19 F. Luan, S. Zhang, F. Wei and X. Zhuang, Microchem. J., 2018, 143, 450.

20 C. Tian, L. Wang, F. Luan and X. Zhuang, Talanta, 2019, 191, 103.

21 X. Zhuang, D. Chen, S. Zhang, F. Luan and L. Chen, Microchim. Acta, 2018, 185, 166.

22 D. Chen, X. Zhuang, J. Zhai, Y. Zheng, H. Lu and L. Chen, Sens. Actuators, B, 2018, 255, 1500.

23 W. Meng, X. Duan, Y. Xu and X. Duan, ACS Nano, 2016, 10, 7231.

24 X. H. Xia, D. L. Chao, Y. Q. Zhang, Z. X. Shen and H. J. Fan, Nano Today, 2014, 9, 785.

25 S. Mao, G. Lu and J. Chen, Nanoscale, 2015, 7, 6924.

26 X. Zheng, X. Xiong, J. Yang, D. Chen, R. Jian and L. Lin, Chem. Eng. J., 2017, 333, 153.

27 C. Santhosh, V. Velmurugan, G. Jacob, G. Jeong, S. K. Jeong, A. N. Grace and A. Bhatnagar, Chem. Eng. J., 2016, 306, 1116.

28 H. Bi, X. Xie, K. Yin, Y. Zhou, S. Wan, L. He, F. Xu, F. Banhart, L. Sun and R. S. Ruoff, Adv. Funct. Mater., 2012, 22, 4421.

29 L. Zhao, B. Yu, F. Xue, J. Xie, X. Zhang, R. Wu, R. Wang, Z. Hu and S. T. Yang, J. Hazard. Mater., 2015, 286, 449.

30 F. Liu, S. Chung, G. Oh and T. S. Seo, ACS Appl. Mater. Interfaces, 2012, 4, 922.

31 L. Yang, F. Jia and S. Song, Sep. Purif. Technol., 2017, 186, 63.

32 S. Rangel, L. F. Magana and L. E. Sansores, ChemPhysChem, 2014, 15, 4042.

33 L. Yang, F. Jia, B. Yang and S. Song, Results Phys., 2017, 7, 4089.

34 B. Fotoohi and L. Mercier, Sep. Purif. Technol., 2015, 139, 14.

35 R. G. Pearson, J. Am. Ceram. Soc., 1963, 85, 3533-3539.

36 H. L. Ma, Y. Zhang, Q. H. Hu, D. Yan, Z. Z. Yu and M. Zhai, J. Mater. Chem., 2012, 22, 5914.
37 X. Zhang, Z. Sui, B. Xu, S. Yue, Y. Luo, W. Zhan and B. Liu, J. Mater. Chem., 2011, 21, 6494.

38 M. A. Worsley, P. J. Pauzauskie, T. Y. Olson, J. Biener, J. H. Satcher and T. F. Baumann, J. Am. Chem. Soc., 2010, 132, 14067.

39 S. Karkar, S. Debnath, P. De, K. Parashar, K. Pillay, P. Sashikumar and U. C. Ghosh, Chem. Eng. J., 2016, 306, 269.

40 J. Chen, Q. Chen and Q. Ma, J. Colloid Interface Sci., 2012, 370, 32.

41 M. Veerapandian, M. H. Lee, K. Krishnamoorthy and K. Yun, Carbon, 2012, 50, 4228.

42 D. S. Sutar, P. K. Narayanam, G. Singh, V. D. Botcha, S. S. Talwar, R. S. Srinivasa and S. S. Major, Thin Solid Films, 2012, 520, 5991.

43 G. Wang, B. Wang, J. Park, J. Yang, X. Shen and J. Yao, Carbon, 2009, 47, 68.

44 J. Ma, C. Liu, R. Li and J. Wang, e-Polym., 2012, 33, 386.

45 A. V. Murugan, T. Muraliganth and A. Manthiram, Chem. Mater., 2010, 22, 2692.

46 X. Li, H. Wang, J. T. Robinson, H. Sanchez, G. Diankov and H. Dai, J. Am. Chem. Soc., 2009, 131, 15939.

47 L. Sun, L. Wang, C. Tian, T. Tan, Y. Xie, K. Shi, M. Li and H. Fu, RSC Adv., 2012, 2, 4498.

48 S. C. W. Sakti, D. Siswanta and N. Nuryono, Pure Appl. Chem., 2012, 85, 211.

49 G. V. Myasoedova, I. I. Antokol Skaja and S. B. Savvin, Talanta, 1985, 32, 1105.

50 S. B. Savvin, I. I. Antokol Skaja, G. V. Myasoedova, L. I. Bolshakova and O. P. Shvoeva, J. Chromatogr. A, 1974, $102,287$.

51 V. Subramanyan and L. Jothinathan, $R S C A d v ., 2018,8$, 27045. 